\title{
OS DESASTRES AMBIENTAIS BRASILEIROS E A PANDEMIA DA COVID-19 COMO DESPOJOS PARA AS NOVAS GERAÇÕES: A CATEGORIA JURÍDICA DA FRATERNIDADE COMO RENASCIMENTO
}

Joana Ribeiro ${ }^{1}$

Carolina Medeiros Bahia ${ }^{2}$

DOI: https://doi.org/10.47306/978-65-88213-03-2.368-381

Sumário: 1 Introdução; 2 Sociedade de risco e sociedade de consumo como motivos dos desastres de Mariana, de Brumadinho, do litoral do Nordeste e das queimadas da Amazônia; 3 Direitos das novas e futuras gerações: o caminho da fraternidade; 4 Considerações Finais; Referências.

\section{Introdução}

É possível conviver em um meio ambiente equilibrado e debelar as desigualdades sociais e econômicas, propiciando às presentes e futuras gerações uma vida saudável, em um planeta de convivência em paz e respeito entre a diversidade dos seres humanos e com todos seres vivos e habitats?

Eis os desafios das Nações Unidas, traduzidos na Agenda 2030, como monumento simbólico e diretivo, para a concretização de transformações reais buscadas para a próxima década.

O planeta, com seus recursos escassos e sujeitos à exploração desenfreada pela sociedade de consumo, está sendo destruído em velocidade até então nunca vista, pela imensa contaminação causada pelos seres humanos e suas tecnologias, gerando uma sociedade de risco.

As tragédias de Mariana de 2015 e de Brumadinho de 2019, cujas feridas ainda persistiam abertas pelas vidas humanas perdidas e pela destruição e poluição ambiental sem precedentes na história do Brasil, demonstraram o quanto o desafio das Nações Unidas é ignorado pelas mineradoras e os grandes poluidores do Mundo, na qual o capital e uma sociedade baseada no egoísmo e no lucro particular reina de forma hegemônica, sustenta o capitalismo e financia as campanhas políticas nos Estados Democráticos.

\footnotetext{
${ }^{1}$ Especialista em Processo Civil pelo sistema LFG (2018). Mestranda em Direito pelo Programa de Mestrado Profissional em Direito da Universidade Federal de Santa Catarina. Juíza de Direito em Santa Catarina, desde 2004.

${ }^{2}$ Doutora em Direito pela Universidade Federal de Santa Catarina. Membro do GPDA/UFSC. Professora no Curso de Graduação e nos Programas de Mestrado Acadêmico e Profissional do CCJ/UFSC.
} 
O advento da pandemia da covid-19 não escolheu vítimas, espalhou-se pelo mundo, mas, como sempre, são os mais vulneráveis os mais atingidos, justamente os mais pobres e mais frágeis de saúde, bem-estar e desenvolvimento humano, que representam as vítimas, em número impactante de mortes pelo Mundo e no Brasil.

Enquanto vários países reduziram suas emissões de gás carbônico em razão das regras da quarentena e do isolamento social, o Brasil divergiu ${ }^{3}$, embalado em uma orientação subliminar do Governo Federal, protagonizada pelo Ministro do Meio-Ambiente e de uma política de deterioração dos meios de proteção, que foi dita expressamente em reunião ministerial de 22 de abril de 2020, posteriormente tornada pública por decisão do Supremo Tribunal Federal ${ }^{4}$.

Nesta sociedade tão desigual, surge a categoria jurídica da fraternidade como uma via de esperança, por meio da solidariedade e do reconhecimento de que somos todos irmãos e precisamos deixar heranças e não despojos para as novas gerações.

Este é o tema deste artigo, escrito com o objetivo de oferecer a categoria jurídica da Fraternidade, advinda do cristianismo, mas secularizada pelo legado da Revolução Francesa e que ingressou como modelo de sociedade no Brasil, a partir do preâmbulo da Constituição Federal de 1988, para oferecer uma categoria jurídica que garanta esperança de vida às novas gerações.

Para tanto, utilizando-se como metodologia o método de abordagem dedutivo, por meio da técnica de pesquisa bibliográfica e reportagens jornalísticas de veículos de imprensa profissionais, objetiva-se oferecer uma proposta de perspectiva para o futuro, a partir das práticas que têm como referência a categoria jurídica da fraternidade.

\footnotetext{
3 "Uma análise feita pelo Observatório do Clima (OC) indica que as emissões de gases do efeito estufa do Brasil podem subir entre $10 \%$ e $20 \%$ em 2020 em relação a 2018 . No mundo, a recessão decorrente da pandemia de Covid-19 pode resultar em redução nas emissões mundiais de $6 \%$ em 2020, a maior já registrada desde os anos 1990". (FOLHA DE SÃO PAULO, 2020a).

4 "O ministro do Meio Ambiente, Ricardo Salles, defendeu em reunião ministerial no final de abril que o governo federal aproveite a crise sanitária do novo coronavírus para aprovar reformas infralegais, incluindo alterações ambientais. As declarações do ministro foram registradas em vídeo do encontro gravado pelo Palácio do Planalto e cujo conteúdo foi disponibilizado nesta sexta-feira (22) pelo ministro do STF (Supremo Tribunal Federal) Celso de Mello. Em seu discurso, Salles ressalta que é hora da edição de medidas de desregulamentação e simplificação, uma vez que os veículos de imprensa estão, neste momento, concentrados no combate à pandemia de Covid-19. Precisa ter um esforço nosso aqui enquanto estamos nesse momento de tranquilidade no aspecto de cobertura de imprensa, porque só fala de Covid, e ir passando a boiada e mudando todo o regramento e simplificando normas", disse" (FOLHA DE SÃO PAULO, 2020d).
} 
Com apenas dois itens de análise, o primeiro item aborda os despojos recentes do Brasil e da pandemia da covid-19, enquanto que o segundo trata dos fundamentos da categoria jurídica da fraternidade.

\section{Sociedade de risco e sociedade de consumo como motivos dos desastres de Mariana, de Brumadinho, do litoral do Nordeste e das queimadas da Amazônia}

Os desastres de Mariana e Brumadinho, em Minas-Gerais - seguidos do desastre do derramamento de óleo no litoral do Nordeste e das queimadas da Amazônia - despertam para o absurdo estágio em que o Brasil avançou no capitalismo sem controle, na sociedade de consumo desigual e egoísta, que encaminham o Brasil à máxima expressão da "sociedade de risco", cunhada por ULRICH BECK.

Para BECK, o desenvolvimento da sociedade industrial propõe uma ruptura para um período da pós-modernidade, colocando a humanidade em risco constante. Impactado com o acidente de Chernobyl, em que vislumbrou a indiscernibilidade dos perigos, com a dependência do saber e a supranacionalidade dos danos, nominou-a "desapropriação ecológica", na qual não cabe a análise da sociedade a partir das classes, pois há um universalismo de ameaças, independente dos lugares onde são produzidas, gerando um fatalismo ecológico. (2011, p. 4143).

Nessa perspectiva, se o risco na Idade Média era visto como possibilidade de risco objetivo, de origem natural, como força maior oriunda das forças da natureza; na Idade Moderna, os riscos tomam outra dimensão, com a possibilidade da destruição da vida na terra. (BAHIA, 2012, p. 30).

Nesta sociedade, há a falência dos padrões de segurança; a constituição de uma sociedade de risco global; a irresponsabilidade organizada, por meio do "movimento circular entre a normalização simbólica e as permanentes ameaças e distribuição materiais", tornando até intencionalmente "invisíveis as origens e consequências sociais dos perigos ecológicos" em grande escala. (BAHIA, 2012, p. 55-56).

Beck então apresenta três tipos de ameaças globais na sociedade de risco: a) a destruição ecológica e os perigos tecnológicos motivados pela riqueza; b) os riscos diretamente relacionados com a pobreza, por alimentarem a destruição ambiental; c) as armas de destruição em massa, sem falar na interação entre estas, como a destruição ecológica e as guerras, acentuadas pelas consequências da modernização incompleta. Ao passo que estas ameaças não se sujeitam à delimitação social, espacial e temporal, nem às regras de culpa e causalidade que 
propiciem um sistema de seguro e compensação dos danos, avassaladores em fronteiras. (BAHIA, 2012, p. 61-62).

Pois foi o que exatamente ocorreu em Mariana, enquadrada na ameaça cunhada por Beck, pelo perigo tecnológico motivado pela busca desenfreada de riqueza.

Pois a exploração excessiva e irresponsável do meio-ambiente propiciou anos de lucros para a empresa Samarco (propriedade das duas maiores mineradoras do mundo: A Vale e a BHP Billiton), ao preço da vida de inúmeras pessoas e do meio de sobrevivência de diversas formas de vida, devastando o meio-ambiente em proporções até então nunca vividas no país: “34 milhões de metros cúbicos de rejeitos de minério de ferro despejados na natureza; cerca de 660 quilômetros percorridos pela lama no curso do Rio Doce; 38 municípios atingidos; 14 toneladas de peixes mortos recolhidos no rio; centenas de milhares de moradores da bacia sem água potável”. Como anota a jornalista SERRA, apesar dos números absurdos, ainda assim eles “não são capazes de traduzir a dimensão humana de uma catástrofe como essa" (2018, p.1314).

A viagem da lama provocou dezenove mortes, devastou os distritos da Cidade de Mariana, Bento Rodrigues e Paracatu de Baixo, seguindo forte com material sólido e utilizandose do Rio Gualaxo do Norte como condutor de detritos, alastrando-se com total violência por povoados, soterrou nascentes de rios, alterou o relevo e a composição do solo e das águas, destruiu uma usina hidrelétrica e danificou outras quatro usinas por onde passou, atingindo o Rio Carmo até a confluência com o Rio Piranga, que formam o Rio Doce, promovendo o Rio Doce a um derramamento hemorrágico descontrolado até o litoral do Espírito Santo, após a viagem por 660 quilómetros. (SERRA, 2018, p.41-42).

“As perdas da fauna e da flora foram colossais. Árvores de até 20 metros foram arrancadas das margens no trecho até Candonga", destruindo 20,47\% da pouca Mata Atlântica, na maior área contínua de Mata Atlântica que restou em Minas Gerais, que possuía apenas $11,7 \%$ de matas originais. (SERRA, 2018, p.41-42).

Apesar de várias ações de emergência para contenção, a chegada o Rio Doce ao mar, além da contaminação da água, deixou outros efeitos de difícil reversão: "a destruição de habitats, de áreas consideradas 'berçários', o soterramento de lagoas e nascentes e o impacto sobre estuários, manguezais e restingas". (SERRA, 2018, p.42-47).

No mar, a mancha de lama altamente contaminada por arsênio, cádmio, chumbo, cromo, níquel, mercúrio, cobre, ferro, manganês e alumínio era tão vasta que era vista pelos satélites da Nasa. Dividiu-se para três regiões marítimas: alcançando Abrólhos-BA de um lado, duas unidades de conservação do Espírito Santo de outro, enquanto uma Terceira parte 
permaneceu na foz, atingindo peixes, golfinhos, corais, algas, aves, tartarugas, em época de procriação, e animais que compõem toda uma cadeia alimentar do ambiente marinho, o que a ICMBio analisou comprometer o ambiente marinho por várias décadas e risco de ressuspensão do sedimento, a cada novo fenômeno natural de ressurgência de ventos fortes. (SERRA, 2018, p.50-51).

Em 1874 o minerologista francês Claude-Henri Gorceix lançou a frase: "Minas é um coração de ouro num peito de ferro". Enquanto em cinco vezes, três anos consecutivos: 2013, 2014 e 2015, a Samarco venceu o prêmio Maiores e Melhores da Revista Exame, com faturamento de 2,6 bilhões de dólares e lucro de um bilhão de dólares em 2014, graças ao aumento de produção de 25 bilhões de toneladas de pelotas de minério de ferro, um aumento de 15,4\% em relação a 2013. Em novembro de 2015 ocorreu o desastre. (SERRA, 2018, p.5594).

E, em 2018, Cristina Serra demonstrou que a tragédia de 2015 começou com o licenciamento irregular: "megaempreendimentos com potencial poluidor conseguem autorização para funcionar, ignorando ou contornando exigências legais”. (SERRA, 2018, p. 124).

O Sistema de Governança da Samarco previu a ruptura da barragem por liquefação, exatamente como ocorreu, mas com 7 meses de antecedência, com observância de vários defeitos e encaminhamentos, contudo, a mineradora não seguiu a recomendação. (SERRA, 2018, p.179-183).

Tampouco havia gerência de risco. Isso porque a liberação das licenças é feita com base no financiamento de campanhas eleitorais para deputados e governadores do Estado de Minas Gerais e na ameaça de que, não aceita a barragem, não haverá empregos, nem pagamento de impostos, portanto, as obras são liberadas em uma indústria de laudos favoráveis à implantação da atividade de risco, paralelo a isso, "chama a atenção a presença de comunidades empobrecidas vivendo em casebres e barracos, às margens do rio", em nítida situação contrastante com o polo econômico que atrai toda cadeia produtiva, que gera riqueza e tributos. (SERRA, 2018, p.242-373).

Nas palavras do Promotor de Justiça que atuou nas investigações no primeiro ano da tragédia, Eduardo Ferreira Pinto, que refletiu sobre sua atuação e desdobramentos finais do caso: “O rompimento é resultado da ineficácia e omissão nas políticas públicas ambientais (...) trata da vida humana com uma externalidade da atividade econômica", no qual prepondera a regra da operação do empreendimento em busca de lucro, em detrimento do controle e uso racional dos recursos ambientais. (SERRA, 2018, p.431). 
O membro do Ministério Público estava certo na previsão racional de nova tragédia, sob a ótica de que a vida humana é uma externalidade da atividade econômica e há descontrole dos recursos ambientais, pois em 25 de janeiro 2019, menos de 4 anos após, ocorreu a tragédia de Brumadinho, uma tragédia humana ainda maior. E o que os dois eventos tem de comum?

"Mortes em longa escala, destruição ambiental, omissão do poder público, ambição, lucro e negligência do setor privado", conforme investigação que demonstrou "A Engenharia de um Crime", na obra de RAGAZZI E ROCHA, de 2019.

Com mais de 248 vítimas identificadas, a partir de mais de 730 segmentos corpóreos e outras vítimas ainda não encontradas, o total de 270 mortes causou revolta, representando a maior tragédia socioambiental da história do Brasil. A frase: "Não foi acidente", estampada nas camisas das pessoas, tem sentido, pois a Vale sabia dos riscos elevados de ruptura da Mina do Córrego do Feijão desde o segundo semestre de 2017 e podia ter evitado as mortes e a tragédia ambiental (RAGAZZI; ROCHA, 2019, p.182-190).

Não bastasse a tragédia de Brumadinho do início de 2019, no mesmo ano, o litoral do Brasil viveu o pior dano ambiental do Nordeste, atingido com manchas de óleo cru, de 21 quilômetros quadrados em uma parte e 3,3 quilômetros quadrados em outra, já afetando manguezais e rios importantes da região (FOLHA DE SÃO PAULO, 2019b).

$\mathrm{Na}$ visão dos juristas MORATO LEITE e AYALA, trata-se de uma catástrofe ambiental que alcançou mais 170 praias, de nove estados da região Nordeste, mais de 2.100 quilômetros da costa brasileira, 12 unidades de conservação, morte de muitos animais da fauna aquática marinha, "perda de biodiversidade, berçários de tartarugas e bens ecológicos, contaminação dos oceanos e rios, entre outros bens da natureza". Além de afetar as atividades econômicas, como o turismo, a pesca e toda a sociedade de forma difusa (2019).

Contextualizando a tragédia, sob a ótica da sociedade de risco definida por BECK, os autores acusam o poder público de morosidade, por deixarem de deflagrar ações do Plano Nacional de Contingência (PNC) para Incidentes de Poluição por Óleo em Águas sob Jurisdição Nacional (Decreto 8.127/2013), ignorarem a disposição da Lei 9.966/2000, que no artigo 28 atribuiu ao Ministério do Meio Ambiente a responsabilidades pela identificação, localização e definição dos limites das áreas ecologicamente sensíveis, quando da ocorrência de poluição provocada por óleo e outras substâncias nocivas ou perigosas em águas brasileiras (MORATO LEITE; AYALA, 2019).

Enquanto que o Decreto Presidencial 9.759/2019, que extinguiu indiscriminadamente várias instâncias colegiadas de interesses difusos e coletivos, atingiu mecanismos de proteção ambiental, pela extinção de duas estruturas fundamentais para a execução do Plano Nacional 
de Contingência, que são o Comitê Executivo e o Comitê de Suporte que, pela ausência, não puderam deflagrar o plano, evidenciando a relação de causalidade entre os danos que se estendem na costa nordestina e a ocorrência e a contribuição de comportamentos omissivos estatais, que poderiam ter atuado e cuja omissão determinaram a magnitude do cenário. (MORATO LEITE; AYALA, 2019)

Enquanto isso, a Amazônia sofreu ataques humanos com queimadas e desmatamento descontrolados e criminosos em 2019, que indignaram a comunidade nacional e internacional (FOLHA DE SÃO PAULO, 2019a).

Após negar a veracidade dos registros das queimadas da Amazônia em 2019, corroer o Fundo Amazônia e desestruturar o IBAMA e o ICMBIO ${ }^{5}$, em uma mensagem subliminar de apoio às queimadas e às grilagens, por meio da MP 19, que visa regularização fundiária ${ }^{6}$, no fatídico ano da sobrevivência à pandemia da covid-19, o teor da revelação da gravação de uma reunião ministerial confirmou a real intenção do Governo Federal, que é destruir o meioambiente, facilitando licenças (Ministro do Meio-Ambiente Ricardo Salles ${ }^{7}$ ), enquanto o Brasil atingia recordes de mortes pela covid-19.

Luiza Lima, porta-voz de Políticas Públicas do Greenpeace Brasil, disse que a fala 'deixa claro aquilo que a sociedade vem denunciando desde o primeiro dia de mandato deste governo, o projeto de desmantelamento das condições de proteção ambiental do país, um ministro de Meio Ambiente usa até a morte das vítimas da pandemia para passar violentamente essa política de destruição'.

'A sociedade segue atenta, a Justiça Federal julgando seus atos, e os satélites que medem o aumento do desmatamento atestando o resultado de sua política. Bolsonaro ganhou as eleições, mas não ganhou um cheque em branco para acabar com a floresta e os povos indígenas, os ministros gostem ou não', afirmou em nota (FOLHA DE SÃO PAULO, 2020b).

Lamentavelmente, as tragédias brasileiras se inserem no contexto da sociedade de risco, que destrói vidas humanas (como se fossem externalidades) e causam desastres ecológicos ainda não dimensionados em sua totalidade, por atos de seres humanos voltados apenas ao lucro, enquanto os "herdeiros" deste meio ambiente degradado são as atuais crianças, adolescentes e as futuras gerações.

A covid-19 chegou ao Brasil encontrando estruturas frágeis de proteção da sua população, tanto em termos de sistema de saúde sobrecarregado - em forte judicialização,

\footnotetext{
${ }^{5}$ FOLHA DE SÃO PAULO, 2020b.

6 (BBC BRASIL. Como a MP da "grilagem" pode mudar o mapa de regiões da Amazônia. Disponível em: https://www.bbc.com/portuguese/brasil-51071810. Acesso em: 02 jun. 2020).

7 "Para o governo Bolsonaro, floresta boa é floresta morta. Os resultados dessa política antiambiental estão bem à vista: a área desmatada na Amazônia, que já havia saltado 29,5\% em 2019 e chegado a 9.762 km², um recorde na década, prossegue em alta. Já se projeta que a devastação possa alcançar mais de $12.000 \mathrm{~km}^{2}$ neste ano". (FOLHA DE SÃO PAULO, 2020b).
} 
despreparado e dependente de insumos e materiais importados - como de uma economia desorganizada, sem um plano de oferta de sustento para a necessária quarentena recomendada pela Organização Mundial da Saúde.

A desordem econômica provocada pela passagem do vírus carreou mais discursos em direção à morte, diante da desorientação à população e com obstáculos à necessária fluidez para as ações no âmbito da saúde (O GLOBO, 2020).

Sem um plano concreto de oferta de proteção à quarentena e com discurso baseado na negação da gravidade da doença e no ódio contra as instituições, o Brasil manchou o verde da sua bandeira - que representava a exuberância da mata - pela imagem nacional e internacional corroída pelo luto das vidas perdidas pela covid-19, pela lama escura das mineradoras e pelas cinzas das queimadas na Amazônia.

Baudrillard já descrevia a sociedade de consumo em referência ao discurso negativo que constitui a residência secundária do intelectual, pois se a Idade Média se equilibrava em Deus e um representante do Mal, a nossa se baseia no consumo, na sua denúncia, contudo, porém se naquela era possível organizar heresias e seitas de magia negra, nesta a magia é branca e a heresia é impossível na abundância: "E a alvura profilática de uma sociedade saturada, de uma sociedade sem vertigem e sem história, com o outro mito de si mesma" (BAUDRILLARD, 2007, p. 268).

Segundo o Relatório Fronteiras 2016, sobre questões emergentes de preocupação ambiental do Programa das Nações Unidas para o Meio Ambiente - PNUMA (2016): (a) 60\% de todas as doenças infecciosas em humanos são zoonóticas assim como $75 \%$ de todas as doenças infecciosas emergentes; (b) enquanto muitas dessas doenças se originam na vida selvagem, a pecuária e a criação intensiva de animais sempre servem como uma ponte epidemiológica entre a vida selvagem e as infecções humanas; (c) além disso, o surgimento de doenças zoonóticas está sempre associada a mudanças ambientais ou distúrbios ecológicos, tal como agricultura intensiva, assentamentos humanos ou invasão de florestas e outros habitats.

O documento ainda alerta que as mudanças climáticas são o principal fator da emergência das zoonoses, pois elas influenciam as condições ambientais que facilitam ou dificultam a sobrevivência, reprodução, abundância e distribuição de patógenos, vetores e hospedeiros, assim como a transmissão de doenças e a frequência de surtos (PNUMA, 2016).

Por isso, além da necessidade de maiores investimentos em vigilância e na ampliação da rápida capacidade de resposta às necessidades urgentes, segundo o PNUMA, é fundamental que as medidas a serem adotadas pelos Estados dirijam-se à raiz do problema: o fato de que as 
atividades humanas estão impondo um stress extremo aos ecossistemas e à sua capacidade de funcionar (PNUMA, 2016).

O grande estímulo ao consumo, associado à apressada obsolescência de todos os produtos disponibilizados no mercado, tem como consequências: o permanente incremento da extração de recursos naturais, a disposição inadequada de resíduos na natureza, a perda da biodiversidade, a constante ameaça à capacidade de resiliência do sistema e a ultrapassagem dos limites biofísicos planetários.

Deste modo, só será possível evitar novas pandemias, como a atual, se reduzirmos os padrões de produção e consumo atuais, de maneira que possamos manter os limites dos processos e subsistemas planetários, preservando a sua capacidade de resiliência.

\section{O direito das novas e futuras gerações: o caminho da fraternidade}

A adolescente Greta Thunber, de 16 anos e outros quinzes jovens com idades entre 08 e 17 anos apresentaram ação formal na UNICEF, em setembro, contra os países signatários da Convenção sobre os Direitos das Crianças de 1989, ao argumento de que a falta de ação dos governos em conter a crise climática, representa o não cumprimento do compromisso que assinaram e que 196 nações ratificaram, na proteção do direito à vida e à saúde das crianças. Discurso impactante e repetido em vários veículos da imprensa foi a afirmação de Greta a uma plateia de Chefes de Estado: "Isso está tudo errado. Eu deveria estar na escola estudando. Mas vocês procuram os jovens para ter esperança? Como vocês ousam? " (FOLHA DE SÃO PAULO, 2019c).

Enquanto vozes apoiavam seu discurso de proteção ao meio ambiente para as crianças e adolescentes e para as futuras gerações, críticas, fake news e ameaças contra a adolescente passaram a ser mundiais (FOLHA, 2019d), porém, a covid-19 vem calando as vozes negacionistas da proteção ambiental ${ }^{8}$ e o mundo vive atualmente proporções sem precedentes da pandemia da covid-19, que desvendou a face tenebrosa da sociedade de consumo e de risco, até então só vivida e sentida pela pobreza, como resultado do capitalismo.

\footnotetext{
8 "Pesquisadores de zoonoses (doenças transmitidas de animais para o ser humano) observam o risco do surgimento de outras epidemias caso o habitat dos morcegos continue sendo invadido ou destruído. Contudo, é importante destacar que esses animais são de extrema importância para a dinâmica ecológica do planeta e a sua caça causaria um grande impacto biológico". (INSTITUTO HUMANITAS UNISINOS. Preservação ambiental é a chave para a contenção de doenças. Disponível em: http://www.ihu.unisinos.br/78-noticias/596921-preservacao-ambiental-ea-chave-para-a-contencao-de-doencas. Acesso em: 02 jun. 2020).
} 
COMPARATTO ensina que, em contraste com o que ocorreu em todas as civilizações anteriores, na capitalista, a busca incessante pelo interesse material particular sempre levou ao predomínio da moral do egoísmo (2017, p. 34).

E como ultrapassar esta fase? Qual sociedade queremos? Quais garantias jurídicas?

Como ensina VERONESE, "ou nos reconhecemos no humano e no que há em cada um ou, nos perderemos enquanto humanidade" (2019, p. 29).

Este é o ponto de partida!

FONSECA sustenta que a história já demonstrou que a realização da igualdade à custa da liberdade, leva ao autoritarismo, enquanto que o sacrifício da igualdade, em nome da liberdade, leva à sociedade ao desastre $(2019$, p. 167) que foi demonstrado no item I: uma sociedade de risco e de consumo, na ampla liberdade do mercado.

BRITTO salienta que a economia não se restringe mais aos ganhos tecnológicos e de produtividade, mas precisa necessariamente passar a respeitar a preservação do meio ambiente “e às postulações de segurança social e de uma decidida integração comunitária (logo fraternal)", de modo que o Estado deve exibir sua dimensão política e de soberania nacional, autossustentado e sem dependência externa, mas também em outras três dimensões: a) a justiça social, com o compartilhamento dos frutos com todos os extratos da sociedade; b) o respeito aos que experimentam o obstáculo da discriminação social, com as ações afirmativas necessárias e; c) “a absorção da ideia de equilíbrio ecológico enquanto elemento de sua própria definição" (2016, p. 28-29).

Trata-se da compreensão do "Direito enquanto meio, o humanismo enquanto fim" (BRITTO, 2016, p. 37).

O humanismo é o "culto", a exaltação à humanidade, "contando que tal reverência também se dê perante cada qual das células de que essa humanidade se compõe", quando então sustenta que não pode haver humanismo sem os "humanitas", República sem os republicanos, “como é impossível praticar a democracia sem democratas" (BRITTO, 2016, p. 52-54).

A partir das lições de BRITTO, FONSECA explica que a fraternidade é fundamental para a consolidação conjunta na realização da liberdade e da igualdade, sendo que a dignidade da pessoa humana assume a capacidade estruturadora da fraternidade, ao tempo em que por ela é estruturada, tanto na criação do direito objetivo - da função integrativa da hermenêutica constitucional, que pressupõe o reconhecimento da condição humana a todo o modo de pensar em conformidade com a fraternidade - como na dignidade da pessoa humana, como condição de possibilidade de sustentação do projeto político pensado com base na tríade: liberdade, 
igualdade e fraternidade, como núcleo promocional e valorativo do Estado brasileiro (2019, p. 84).

Baseado na validade jurídica do preâmbulo da Constituição Federal de 1988, com base na doutrina e nas decisões do Supremo Tribunal Federal, FONSECA sustenta que "a fraternidade é um direito fundamental autônomo cujo centro axiológico repousa sobre a dignidade da pessoa humana e desenvolve-se como valor com coloração analítica própria”, lembrando ser essencial para a realização harmônica entre a liberdade e a igualdade, como forma de evitar exclusões e com o reconhecimento da alteridade como característica intrínseca à operacionalização na práxis jurídica (2019, p. 99,115-123).

E a Constituição, mais que uma Lei Fundamental do Estado e do provo brasileiro, é a Lei Fundamental de toda a nação brasileira, "sabido que a nação, por ser linha invisível que faz a costura da unidade entre o passado, o presente e o futuro, é instituição que tanto engloba o povo hoje, como o povo de ontem e de amanhã”, daí porque sustenta o autor que a vontade coletiva é "intergeracional desde o seu nascedouro" (BRITTO, 2016, p. 99).

Nas palavras de ABREU:

Acho que está na hora de praticar um certo 'saneamento no mundo das ideias' para
desprogramar o homem dessa brutal capacidade de gerar a dor, a diferença, a infâmia,
a falta de identidade, de reciprocidade, de RESPEITO à identidade de uma VIDA SÓ,
em grupo, na companhia da família, na religião, na região, na ilha ou no continente,
na empresa, no país, no emprego, na vida social, amorosa, no capital, no mercado
mundial, comunitário, planetário, continental, insular, marítimo, submarino,
ambiental, espacial, orbital, estelar de todos os mundos conhecidos e desconhecidos
desse mundo de meu DEUS. (2019, p. 69$)$.

VERONESE afirma que devemos sublimar a nossa condição humana, para pôr em destaque a dignidade, o respeito e a liberdade, propondo um humanismo efetivo e concreto, em busca da construção de uma cultura de paz, baseada no compromisso real com a liberdade e com a tolerância $(2019$, p. 21).

Sua proposta é de consolidação de um projeto societário comprometido com a dignidade da vida humana, com sua felicidade, em uma visão ética e histórica para acreditar "no ser humano, na dignidade da pessoa humana, na edificação de novos valores, através do qual, não cancelando a pessoa, em seu caráter individual, conheça-se o alcance da fraternidade”, sem deixar de reconhecer a diferença entre todos, mas buscando a participação comunitária (VERONESE, 2019, p.25).

Eis a perspectiva do Constitucionalismo fraternal, na convicção de que o constitucionalismo pátrio ultrapassa o liberalismo e a social democracia, para alcançar o constitucionalismo fraternal (ou altruístico) (FONSECA, 2019, p. 170). 
Advindo do Constitucionalismo fraternal de BRITTO a "fraternidade jurídicocontemporânea com natureza jurídica de direito público subjetivo vertical, exigível do Estado no desenvolvimento de suas ações e políticas públicas", como elemento do Estado Democrático de Direito (MOURA, 2017, p. 438).

\section{Conclusão}

Se existe o contágio pelo discurso do ódio e ações baseadas no individualismo e na devastação ambiental, em um ambiente de sociedade capitalista, que assim como a covid-19, é de eficiente disseminação, faremos a difusão da vacina da categoria política da fraternidade, para que a solidariedade e o sentimento de irmandade sejam mais fortes que a busca desenfreada e egoísta pelo lucro, que tanto prejudica o meio ambiente de todos e gera desigualdades sociais.

Que as palavras de empatia minimizem o ódio, para que a sociedade brasileira possa ressurgir dos despojos de Mariana, de Brumadinho, do desastre de óleo no litoral do Nordeste e das queimadas da Amazônia e sobreviva à covid-19, com esperança de mudanças, a partir de ares renovados de altruísmo, de comunidade de vida em um ambiente saudável e de fraternidade, para deixarmos o meio-ambiente devidamente recuperado dos despojos, como forma de justiça para a atual geração das crianças e dos adolescentes e para as futuras gerações!

E enquanto a vacina da categoria política da fraternidade não tiver efeitos contra todos, o remédio é a categoria jurídica da fraternidade, disponível desde 1988, mas reconhecida como valor jurídico pelo Supremo Tribunal Federal no Século XXI, como apta a articular, por si ou conjuntamente com outros remédios constitucionais, a exigência de cumprimento, pelo Estado brasileiro, da obrigação de proteção do meio ambiente para as atuais e as futuras gerações, a preservação da vida e a garantia do Estado promocional de direitos, protetor de sua população, sendo o Judiciário o destinatário da categoria jurídica da fraternidade, na perspectiva do Ministro e Poeta BRITTO, de que o Poder Judiciário é o garantidor da Constituição dirigente e do humanismo.

\section{REFERÊNCIAS}

ABREU, Pedro Manoel [et al]. Acesso à Justiça: novas perspectivas. Florianópolis: Habitus, 2019.

BBC BRASIL. Como a MP da "grilagem" pode mudar o mapa de regiões da Amazônia. Disponível em: https://www.bbc.com/portuguese/brasil-51071810. Acesso em: 02 jun. 2020. 


\section{ASSOCIAÇÃO DE INDICADORES EM DIRIETOS HUMANOS PARA O DESENVOLVIMENTO. AiDH em cadernos. Curitiba-PR, v. 1, 2017.}

BAHIA, Carolina Medeiros. Nexo de Causalidade em face do risco e do dano ao meio ambiente: elementos para um novo tratamento da causalidade no sistema brasileiro de responsabilidade civil ambiental. Tese (Doutorado em Direito) - UFSC. Florianópolis, 2012. BAUDRILLARD, Jean. A sociedade de consumo. Edições 70: Lisboa, 2018.

BAUMAN, Zygmunt. Vida para consumo: a transformação das pessoas em mercadorias. Tradução de Carlos Alberto Medeiros. Rio de Janeiro: Zahar, 2008.

BECK, Ulrich. Sociedade de Risco: rumo a uma outra modernidade. Tradução de Sebastião Nascimento. 2. ed. São Paulo: Editora 34, 2011.

BRITTO, Carlos Ayres. O humanismo como categoria constitucional. Belo Horizonte: Fórum, 2016.

FOLHA DE SÃO PAULO. Desmatamento na Amazônia cresce 96\% em setembro, indicam alertas do Inpe. Disponível em:

https://www1.folha.uol.com.br/ambiente/2019/10/mancha-de-oleo-de-21-quilometrosquadrados-se-aproxima-da-bahia.shtml. Acesso em: 11 out. 2019a.

FOLHA DE SÃO PAULO. Mancha de óleo de 21 quilômetros quadrados se aproxima da Bahia. Disponível em: https://www1.folha.uol.com.br/ambiente/2019/10/desmatamento-naamazonia-cresce-96-em-setembro-indicam-alertas-do-inpe.shtml. Acesso em: 11 out. 2019b.

FOLHA DE SÃO PAULO. Com Greta, jovens fazem queixa formal à UNICEF contra inação de governos. Disponível em:

https://ambiencia.blogfolha.uol.com.br/2019/09/23/com-greta-jovens-fazem-queixa-formal-aunicef-contra-inacao-de-governos/. Acesso em: 25 set. 2019c.

FOLHA DE SÃO PAULO. Greta Thunberg foi de ativista solitária a alvo de ataques em um ano. Disponível em: https://www1.folha.uol.com.br/ambiente/2019/09/greta-thunbergfoi-de-ativista-solitaria-a-alvo-de-ataques-em-um-ano.shtml. Acesso em 27 set. 2019d.

FOLHA DE SÃO PAULO. Mesmo com pandemia, emissões de carbono no Brasil aumentam. Disponível em:

https://www1.folha.uol.com.br/colunas/maragama/2020/05/mesmo-com-pandemia-emissoesde-carbono-no-brasil-aumentam.shtml. Acesso em: 29 maio 2020a.

FOLHA DE SÃO PAULO. Passar a boiada. Disponível em: https://www1.folha.uol.com.br/opiniao/2020/05/passar-a-boiada.shtml. Acesso em: 29 maio $2020 \mathrm{~b}$.

FOLHA DE SÃO PAULO. Salles errou previsão e teve decisões questionadas por imprensa, MPF e Justiça. Disponível em: https://ambiencia.blogfolha.uol.com.br/2020/05/23/salles-errou-previsao-e-teve-decisoesquestionadas-por-imprensa-mpf-e-justica/. Acesso em: 29 maio 2020c. 
FOLHA de SÃO PAUlO. Ministro do Meio Ambiente defende aproveitar crise do coronavírus para "passar a boiada". Disponível em:

https://www1.folha.uol.com.br/ambiente/2020/05/ministro-do-meio-ambiente-defendeaproveitar-crise-do-coronavirus-para-passar-a-boiada.shtml. Acesso em: 29 maio $2020 \mathrm{~d}$.

FOLHA DE SÃO PAULO. Leia a íntegra das falas de Bolsonaro e ministros em reunião ministerial gravada. Disponível em: https://www1.folha.uol.com.br/poder/2020/05/leia-aintegra-das-falas-de-bolsonaro-e-ministros-em-reuniao-ministerial-gravada.shtml. Acesso em: 29 maio 2020e.

FOLHA DE SÃO PAULO. Senadores entrevistados em enquete refutam propostas do "PI da grilagem". Disponível em: https://ambiencia.blogfolha.uol.com.br/2020/05/20/senadoresentrevistados-em-enquete-refutam-propostas-do-pl-da-grilagem/. Acesso em: 29 maio 2020. F

FONECA, Reynaldo Soares. O princípio constitucional da fraternidade: seu resgate no sistema de justiça. Belo Horizonte: Editora D’ Plácido, 2019.

O GLOBO. Queda do segundo ministro da saúde durante a pandemia causa irritação e incredulidade em líderes do congresso. Disponível em:

https://oglobo.globo.com/brasil/queda-de-segundo-ministro-da-saude-durante-pandemiacausa-irritacao-incredulidade-em-lideres-do-congresso-1-24428973. Acesso em: 02 jun. 2020.

PROGRAMA DAS NAÇÕES UNIDAS PARA O MEIO AMBIENTE - PNUMA. Relatório Fronteiras 2016 sobre questões emergentes de preocupação ambiental. Disponível em: https://environmentlive.unep.org/media/docs/assessments/UNEP_Frontiers_2016_report_eme rging_issues_of_environmental_concern.pdf. Acesso em: 16 jun. 2020.

INSTITUTO HUMANITAS UNISINOS. Preservação ambiental é a chave para a contenção de doenças. Disponível em: http://www.ihu.unisinos.br/78-noticias/596921preservacao-ambiental-e-a-chave-para-a-contencao-de-doencas. Acesso em: 02 jun. 2020.

MORATO LEITE. José Rubens; AYALA, Patryck de Araújo. Lições de uma catástrofe anunciada: dano ambiental por vazamento de petróleo na costa do Nordeste e o lugar da responsabilidade civil ambiental na época do Antropocentro. Disponível em:

http://genjuridico.com.br/2019/10/22/vazamento-de-petroleo-nordeste/. Acesso em 30 out. 2019.

NAÇOES UNIDAS. 17 Objetivos para transformar nosso mundo: Agenda 2030 para o desenvolvimento sustentável. Disponível em https://nacoesunidas.org/pos2015/agenda2030/. Acesso em 14 de nov. de 2019.

RAGAZZI, Lucas; ROCHA, Murilo. Brumadinho: a engenharia de um crime. Belo Horizonte: Letramento, 2019.

SERRA, Cristina. Tragédia em Mariana: a história do maior desastre ambiental do Brasil. Rio de Janeiro: Record, 2018.

VERONESE, Josiane Rose Petry. FONSECA, Reynaldo Soares da. Literatura, Direito e Fraternidade - sua incidência no Estatuto da Criança e do Adolescente. Salvador: JusPodivm, 2019. 